\title{
Percutaneous transcatheter aortic valve implantation for degenerated surgical bioprostheses: the first case series in Asia with one-year follow-up
}

Paul Toon Lim Chiam 1,2 MBBS, FRCP, See Hooi Ewe 3 , Yong Koong $\underline{\mathrm{Sin}}^{4,5}$, MBBS, fRCS, Swee Yaw $\underline{\operatorname{Tan}}^{3}$, MBBS, MRCP, Soo Teik $\underline{\mathrm{Lim}}^{3,5}$, MBBS, MRCP, Tian Hai Ko $\underline{\mathrm{h}}^{3,5}$, MBBS, MMed,

Yeow Leng $\underline{\text { Chua }}^{4,5}$, MBBS, FRCS

INTRODUCTION Percutaneous transcatheter aortic valve implantation (TAVI) has become an established therapy for inoperable and high-surgical-risk patients with severe aortic stenosis. Although TAVI in patients with degenerated surgical aortic bioprostheses (i.e. valve-in-valve TAVI) is increasingly reported in Western studies, such data is lacking in Asian patients. We describe the initial experience of valve-in-valve TAVI in Asia.

METHODS Eight patients who underwent valve-in-valve TAVI due to degenerated aortic bioprostheses were enrolled. The mechanism of bioprosthetic valve failure was stenotic, regurgitation or mixed. All procedures were performed via transfemoral arterial access, using the self-expanding CoreValve prosthesis or balloon-expandable SAPIEN XT prosthesis. RESULTS The mean age of the patients was $71.6 \pm 13.2$ years and five were male. Mean duration to surgical bioprosthesis degeneration was $10.2 \pm 4.1$ years. Valve-in-valve TAVI was successfully performed in all patients. CoreValve and SAPIEN XT prostheses were used in six and two patients, respectively. There were no deaths, strokes or permanent pacemaker requirement at 30 days, with one noncardiac mortality at one year. All patients experienced New York Heart Association functional class improvement. Post-procedure mean pressure gradients were $20 \pm 11 \mathrm{mmHg}$ and $22 \pm 8 \mathrm{mmHg}$ at 30 days and one year, respectively. Residual aortic regurgitation (AR) of more than mild severity occurred in one patient at 30 days. At one year, only one patient had mild residual AR.

CONCLUSION In our experience of valve-in-valve TAVI, procedural success was achieved in all patients without adverse events at 30 days. Good clinical and haemodynamic outcomes were sustained at one year.

Keywords: aortic regurgitation, aortic stenosis, bioprosthesis, transcatheter aortic valve implantation, transcatheter aortic valve replacement

\section{INTRODUCTION}

Percutaneous transcatheter aortic valve implantation (TAVI), also known as transcatheter aortic valve replacement, has become the treatment of choice for inoperable patients with severe aortic valve stenosis $^{(1,2)}$ and an alternative treatment to open chest surgical aortic valve replacement (SAVR) in patients at high surgical risk. ${ }^{(3,4)}$ Due to the minimally invasive nature of the technique, valve-in-valve TAVI is increasingly used as an alternative treatment modality in patients with degenerated surgical bioprostheses in the aortic position.

Valve-in-valve TAVI is an attractive option for patients with a previous aortic surgical bioprosthesis; these patients are considered to be at elevated risk for reoperation due to various reasons, including technical difficulties of a scarred chest, advanced patient age and other comorbidities. Several case series, including a large global registry on valve-in-valve TAVI, ${ }^{(5-9)}$ have been reported. However, such data on Asian patients is lacking. We describe the first case series of valve-in-valve TAVI for degenerated aortic surgical bioprostheses in Asia.

\section{METHODS}

Eight consecutive patients who underwent valve-in-valve TAVI in a single centre due to degenerated surgical bioprostheses in the aortic position were included in the study. All patients were evaluated by a multidisciplinary heart team, including two cardiac surgeons, and were deemed to be at elevated risk of redo open heart surgery. Bioprosthetic aortic valve failures were categorised, based on the primary mechanism of failure, into stenotic, regurgitation or mixed (with at least a moderate degree of both stenosis and regurgitation), according to the recommendations of the American Society of Echocardiography. ${ }^{(10)}$

All valve-in-valve TAVI procedures were performed using either the self-expanding CoreValve (Medtronic Inc, Minneapolis, MN, USA) prosthesis (Fig. 1) or the balloon-expandable SAPIEN XT (Edwards Lifesciences, Irvine, CA, USA) prosthesis (Fig. 2). The CoreValve prosthesis consists of three porcine pericardial leaflets sutured within a self-expanding nitinol frame, whereas the SAPIEN XT prosthesis consists of three bovine pericardial leaflets mounted within a balloon-expandable cobalt chromium frame. Both devices were crimped in the procedure suite and inserted in the delivery catheter. All the procedures were performed via transfemoral arterial access.

Patient characteristics, details of previous surgical bioprostheses, and procedural and clinical outcomes were recorded. Procedural success and all adverse clinical outcomes

\footnotetext{
${ }^{1}$ The Heart and Vascular Centre, Mount Elizabeth Medical Centre, ${ }^{2}$ Yong Loo Lin School of Medicine, National University of Singapore, ${ }^{3}$ Department of Cardiology, ${ }^{4}$ Department of Cardiothoracic Surgery, National Heart Centre Singapore, ${ }^{5}$ Duke-NUS Medical School, Singapore

Correspondence: A/Prof Paul Chiam, Senior Consultant, The Heart and Vascular Centre, Mount Elizabeth Medical Centre, 3 Mount Elizabeth, \#08-06, Singapore 228510. paulchiam@heartvascularcentre.com
} 


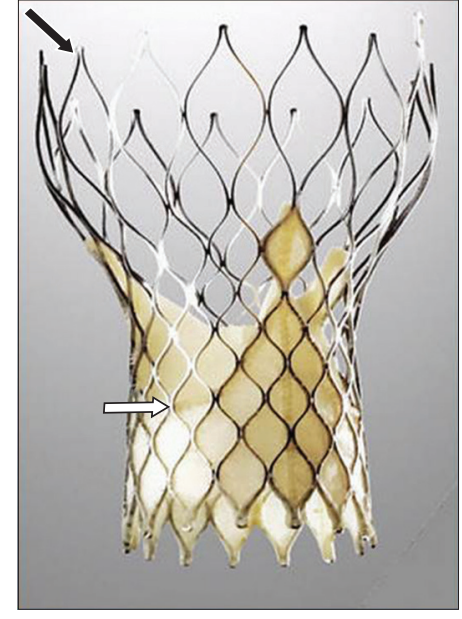

Fig. 1 Photograph shows the self-expanding CoreValve transcatheter heart valve with a nitinol frame (black arrow) and porcine pericardial leaflets (white arrow).

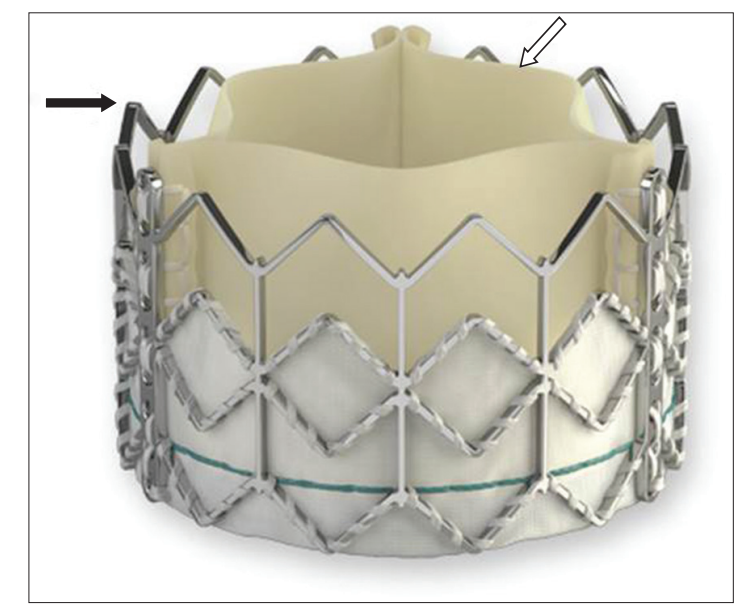

Fig. 2 Photograph shows the balloon-expandable SAPIEN XT transcatheter heart valve with a cobalt chromium frame (black arrow) and bovine pericardial leaflets (white arrow)

and events were defined according to the Valve Academic Research Consortium-2 consensus document. ${ }^{(11)}$ All patients gave their informed consent for the study.

\section{RESULTS}

The mean age of the eight patients was $71.6 \pm 13.2$ years and $5(62.5 \%)$ were male. Their baseline characteristics are summarised in Table I. Previous surgical valves were all stented bioprostheses in the aortic position, and the majority ( $\mathrm{n}=7,87.5 \%$ ) were Carpentier-Edwards (CE) PERIMOUNT bioprostheses. Of note, the majority of the patients ( $n=6,75.0 \%)$ had small surgical prostheses, which were defined as surgical bioprostheses of labelled size $\leq 21 \mathrm{~mm}$ with true inner diameter $\leq 20 \mathrm{~mm}$; in the series, the most common size was $21 \mathrm{~mm}(\mathrm{n}=5$, $62.5 \%$ ). The mean duration to surgical bioprosthesis degeneration was $10.2 \pm 4.1$ years. For mechanisms of bioprosthesis failure, there was an equal number of patients in the stenotic and mixed groups ( $n=3$ in each), while the remaining cases $(n=2)$ were due to regurgitation.

Valve-in-valve TAVI was successfully performed in all patients via the transfemoral approach. The CoreValve prosthesis (Figs. 3 \& 4)
Table I. Baseline characteristics of the patients $(n=8)$.

\begin{tabular}{|c|c|}
\hline Characteristic & No. (\%) \\
\hline Age $^{*}(y r)$ & $71.6 \pm 13.2$ \\
\hline \multicolumn{2}{|l|}{ Gender } \\
\hline Male & $5(62.5)$ \\
\hline Female & $3(37.5)$ \\
\hline Height* (cm) & $161 \pm 12$ \\
\hline Weight* (kg) & $57 \pm 14$ \\
\hline Body surface area* $\left(\mathrm{m}^{2}\right)$ & $1.60 \pm 0.25$ \\
\hline Logistic EuroSCORE* (\%) & $17.8 \pm 8.7$ \\
\hline STS PROM score* (\%) & $5.2 \pm 2.3$ \\
\hline \multicolumn{2}{|l|}{ Comorbidity } \\
\hline Diabetes mellitus & $1(12.5)$ \\
\hline Chronic renal failure & $4(50.0)$ \\
\hline Surgical bioprosthesis duration* (yr) & $10.2 \pm 4.1$ \\
\hline \multicolumn{2}{|l|}{ Surgical valve type/size (mm) } \\
\hline CE PERIMOUNT/19 & $1(12.5)$ \\
\hline CE PERIMOUNT/22 & $5(62.5)$ \\
\hline CE PERIMOUNT/23 & $1(12.5)$ \\
\hline Porcine bioprosthesis ${ }^{\dagger}$ & $1(12.5)$ \\
\hline \multicolumn{2}{|l|}{ NYHA class pre-TAVI } \\
\hline 1 & 0 \\
\hline II & $1(12.5)$ \\
\hline III & $7(87.5)$ \\
\hline IV & 0 \\
\hline \multicolumn{2}{|l|}{ Mechanism of bioprosthesis failure } \\
\hline Stenotic & $3(37.5)$ \\
\hline Regurgitation & $2(25.0)$ \\
\hline Mixed & $3(37.5)$ \\
\hline \multicolumn{2}{|l|}{ Aortic bioprosthesis } \\
\hline $\operatorname{Area}^{*}\left(\mathrm{~cm}^{2}\right)$ & $0.74 \pm 0.27$ \\
\hline Mean pressure gradient* $(\mathrm{mmHg})$ & $41 \pm 16$ \\
\hline Regurgitation (more than mild) & $5(62.5)$ \\
\hline Left ventricular ejection fraction* (\%) & $53 \pm 18$ \\
\hline Moderately severe/severe MR & $2(25.0)$ \\
\hline \multicolumn{2}{|l|}{ Device for valve-in-valve procedure } \\
\hline SAPIEN XT & $2(25.0)$ \\
\hline CoreValve & $6(75.0)$ \\
\hline
\end{tabular}

* Data presented as mean \pm standard deviation. IInner diameter of the prosthesis was $23 \mathrm{~mm}$ and details of the original bioprosthesis were unavailable. CE: Carpentier-Edwards; MR: mitral regurgitation; NYHA: New York Heart Association; STS PROM: Society of Thoracic Surgeons Predicted Risk of Mortality; TAVI: transcatheter aortic valve implantation

was used in six patients and the SAPIEN XT prosthesis (Figs. $5 \& 6$ ) was used in the remaining two patients. There were no deaths or strokes at 30 days. All patients reported significant improvement in New York Heart Association (NYHA) functional classification status and none required permanent pacemaker implantation after the procedure. The in-hospital, 30-day and one-year haemodynamic and clinical outcomes are shown in Table II.

The overall survival rate at one year was $87.5 \%(n=7)$. The only mortality, which was due to pneumonia, occurred in a patient who had end-stage renal failure on haemodialysis at 11 months after the procedure. For the rest of the patients, post-procedure pressure gradients were maintained at 30 days and one year, with 


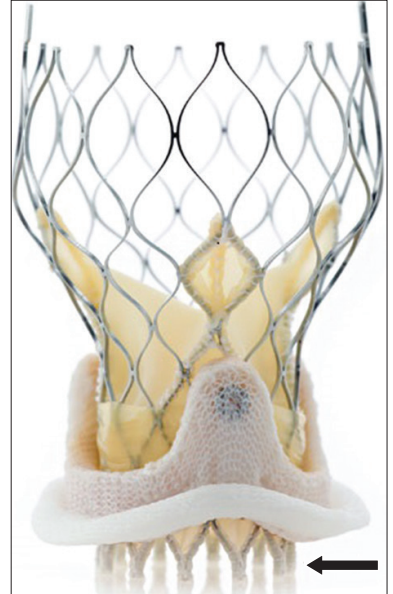

Fig. 3 Photograph shows a self-expanding CoreValve transcatheter heart valve implanted within a surgical bioprosthetic valve. The CoreValve frame (arrow) is seen.
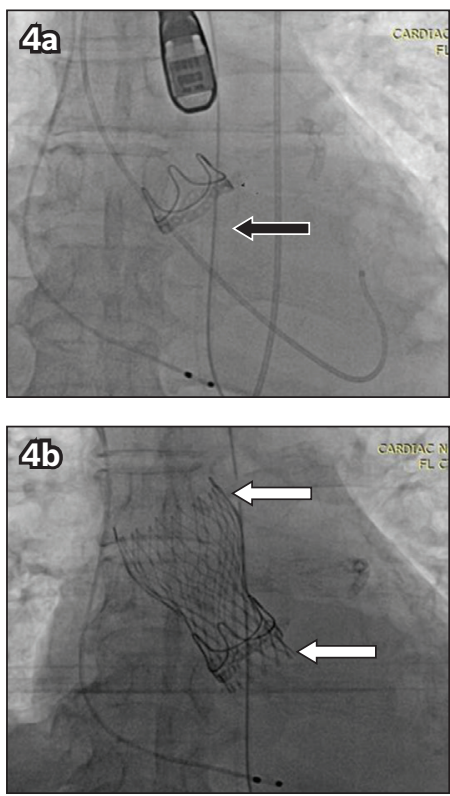

Fig. 4 Fluoroscopic images show (a) a Carpentier-Edwards PERIMOUNT surgical aortic valve bioprosthesis (black arrow) with (b) a self-expanding CoreValve transcatheter heart valve implanted within (white arrows indicate CoreValve frame).

a post-procedure mean pressure gradient (MPG) of $20 \pm 11 \mathrm{mmHg}$ and $22 \pm 8 \mathrm{mmHg}$, respectively (Fig. 7). A significant residual MPG $>20 \mathrm{mmHg}$ was observed in $3(37.5 \%)$ patients. Of these, two patients had CE PERIMOUNT 21-mm valves and one had a CE PERIMOUNT 19-mm valve. Severe patient-prosthesis mismatch (PPM, defined as an indexed effective orifice area $<0.65 \mathrm{~cm}^{2} / \mathrm{m}^{2}$ ) occurred in three patients; one of them had a 19-mm PERIMOUNT bioprosthesis and the other two had 21-mm PERIMOUNT bioprostheses. However, all three patients experienced at least one NYHA functional class improvement and none had any cardiac events at one year. Residual aortic regurgitation (AR) of more than mild severity occurred in only $1(12.5 \%)$ patient at 30 days after the procedure. At one year, nearly all (six out of seven) patients had none or trivial residual $A R$, and only one (i.e. the patient with moderate residual $A R$ at 30 days) had mild residual AR.

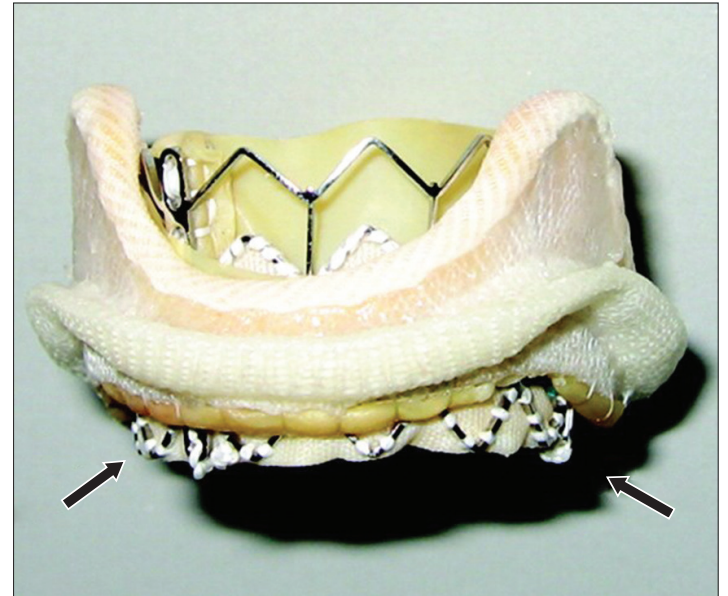

Fig. 5 Photograph shows a balloon-expandable SAPIEN XT transcatheter heart valve implanted with a surgical bioprosthetic valve (arrows indicate SAPIEN XT frame).
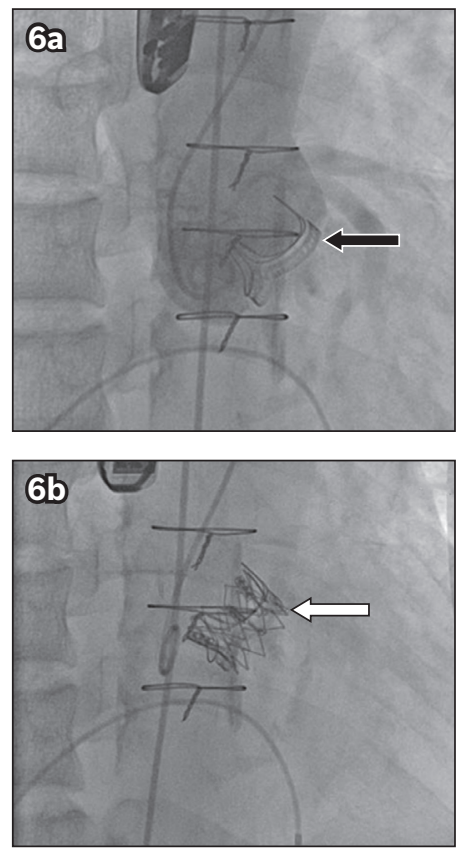

Fig. 6 Fluoroscopic images show (a) a Carpentier-Edwards PERIMOUNT surgical aortic valve bioprosthesis (black arrow) with (b) a balloonexpandable SAPIEN transcatheter heart valve implanted within (white arrow indicates SAPIEN XT frame).

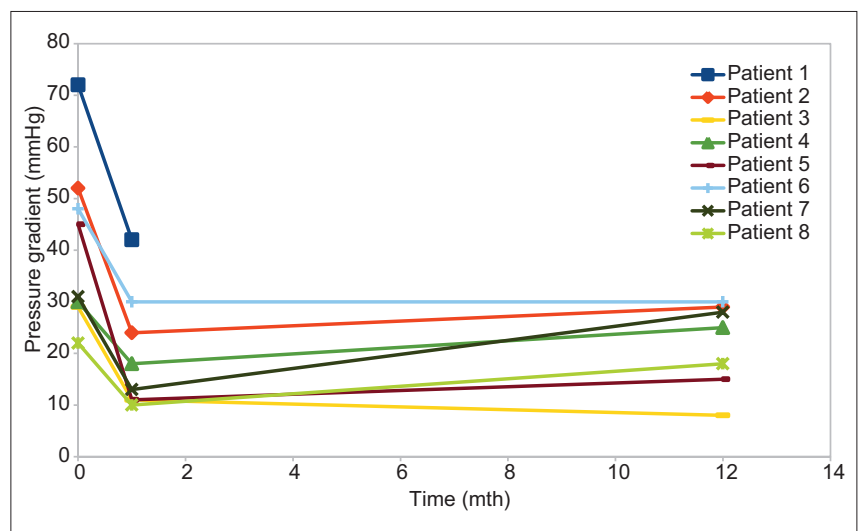

Fig. 7 Line graph shows the changes in mean pressure gradient in the eight patients at baseline, 30 days and one year. 
Table II. Haemodynamic and clinical outcomes $(n=8)$.

\begin{tabular}{|c|c|c|c|}
\hline \multirow[t]{2}{*}{ Parameter } & \multicolumn{3}{|c|}{ No. (\%) } \\
\hline & In-hospital & 30-day & 1-yr \\
\hline Death & 0 & 0 & $1^{+}$ \\
\hline Stroke & 0 & 0 & 0 \\
\hline Myocardial infarction & 0 & 0 & 0 \\
\hline $\begin{array}{l}\text { Major vascular } \\
\text { complication }\end{array}$ & 0 & 0 & 0 \\
\hline Major bleeding & 0 & 0 & 0 \\
\hline Acute kidney injury & 0 & 0 & 0 \\
\hline NYHA class I/II & - & $8(100)$ & $7(100)$ \\
\hline $\begin{array}{l}\text { Permanent pacemaker } \\
\text { implantation }\end{array}$ & 0 & 0 & 0 \\
\hline $\begin{array}{l}\text { Effective orifice area* } \\
\left(\mathrm{cm}^{2}\right)\end{array}$ & - & $1.34 \pm 0.46$ & - \\
\hline \multicolumn{4}{|l|}{ Aortic valve } \\
\hline $\begin{array}{l}\text { Mean pressure } \\
\text { gradient* }(\mathrm{mmHg})\end{array}$ & $20 \pm 11$ & $20 \pm 11$ & $22 \pm 8$ \\
\hline $\begin{array}{l}\text { Regurgitation } \\
\text { (more than mild) }\end{array}$ & $1(12.5)$ & $1(12.5)$ & 0 \\
\hline \multicolumn{4}{|l|}{ Readmission } \\
\hline Valve-related & 0 & 0 & 0 \\
\hline Cardiac & 0 & 0 & 0 \\
\hline Non-cardiac & 0 & 0 & $1(14.3)$ \\
\hline Repeat valve intervention & 0 & 0 & 0 \\
\hline
\end{tabular}

* Data presented as mean \pm standard deviation. tDeath due to pneumonia. NYHA: New York Heart Association

\section{DISCUSSION}

Bioprosthetic valves are increasingly used in preference to mechanical valves in open SAVR, as lifelong oral anticoagulation is not required and its attendant complications can be avoided. A recent study has shown similar long-term survival rates in patients with bioprosthetic and mechanical valves. However, patients with bioprosthetic valves require reoperations due to their limited durability and expected degeneration; ${ }^{(12)}$ those undergoing such reoperations face increased surgical risk due to their more advanced age (compared with their age during the index SAVR) during the redo surgery and scarring in the non-virgin chest. Consequently, valve-in-valve TAVI appears to be an attractive, minimally invasive method of replacing the degenerated surgical aortic bioprosthesis without the need for a reoperation. Several small case series and a global registry have shown that it is a feasible and viable option for patients at high risk. ${ }^{(5-9)}$

In our initial Asian experience of valve-in-valve TAVI in eight patients with degenerated bioprostheses in the aortic position, all procedures were successful, with no mortality or stroke event at 30 days, an $87.5 \%$ survival rate at one year, and a single mortality due to a noncardiac cause. The results compare favourably with those of previous studies, which had 30-day mortality rates of $0 \%-17 \%$, stroke rates of $0 \%-2 \%$, and a one-year survival rate of $85.8 \% .^{(5-9)}$ Although the majority of our patients (75.0\%) had small surgical bioprostheses, the post-procedure 30-day MPG was $20 \mathrm{mmHg}$, which is similar to that reported in the global registry (mean 16.0 [interquartile range 9.1 ] $\mathrm{mmHg}$ ). ${ }^{(8)}$ This is, however, higher than the average expected post-procedure MPG $\left(10 \mathrm{mmHg}\right.$ ) for TAVI in a native aortic valve. ${ }^{(1-4)}$

In the present study, the three patients who had a significant post-procedure residual MPG $>20 \mathrm{mmHg}$ previously had small surgical bioprostheses. The three patients with severe PPM also had small surgical bioprostheses ( $\leq 21-\mathrm{mm}$ PERIMOUNT). The most likely explanation is that these patients already had a high residual MPG and PPM after the initial surgical bioprosthetic valve replacement. ${ }^{(13)}$ Although the TAVI procedure can significantly reduce the pressure gradient, it cannot overcome high baseline pressure gradients or baseline PPM. Larger surgical bioprostheses implanted during the index procedure would reduce baseline PPM and result in better pressure gradients when a valve-invalve TAVI procedure becomes necessary. Although none of our patients with high residual pressure gradients or PPM had any cardiac events at one year, a longer follow-up period was needed to ascertain the clinical impact of PPM.

In the global registry, a residual pressure gradient $>20 \mathrm{mmHg}$ was found in $27 \%$ of patients, although small $(\leq 21 \mathrm{~mm}$ labelled size) surgical bioprostheses accounted for only $29 \%$ of their total population. ${ }^{(8,9)}$ Interestingly, the global registry also observed that the CoreValve prosthesis resulted in a lower pressure gradient in small surgical bioprostheses, compared to the balloonexpandable valve, due to its supra-annular valve design. ${ }^{(8,9)}$ Our series is too small to draw a similar conclusion; however, based on the global registry experience, the CoreValve prosthesis is currently preferred for aortic valve-in-valve TAVI, particularly if the surgical bioprosthesis is $\leq 21 \mathrm{~mm}$ in size.

Only one patient in our series had moderate residual AR at 30 days, which became mild at one year. This patient received a self-expanding transcatheter valve, and it is likely that the continued outward expansion of the frame resulted in better sealing (and thus decreased paravalvular AR) over time. The other surviving patients had none or trivial residual AR. Similarly, this result compares favourably with the global registry, where only $5 \%$ of patients had more than mild residual AR. ${ }^{(8,9)}$ The low rate of post-procedure $A R$, as compared to native valve TAVI, is likely due to the fact that the surgical bioprosthetic ring is circular and the sewing ring is not heavily calcified, allowing for good apposition of the new TAVI prosthesis within the bioprosthetic ring. This is an important finding, as even mild paravalvular AR after TAVI has been shown to result in reduced longer-term survival globally, as compared to patients with no or trivial paravalvular AR following TAVI in native aortic valves. ${ }^{(3,14)}$

One limitation of this study is that it was a small retrospective study among a group of highly selected patients. Thus, the results cannot be generalised to all valve-in-valve TAVI procedures in Asian patients. Furthermore, as nearly all our patients were implanted with a single model of surgical bioprosthesis, results may differ in patients with other types of surgical aortic bioprostheses.

In conclusion, we reported the initial Asian experience of valve-in-valve TAVI for degenerated surgical aortic bioprostheses. Valve-in-valve TAVI was successfully performed in eight patients without adverse events at 30 days; good clinical and 
haemodynamic outcomes were sustained at one year. Valvein-valve TAVI appears to be a feasible, relatively safe and less invasive alternative therapy for Asian patients with degenerated surgical aortic valve bioprostheses. At the initial SAVR, the largestpossible bioprosthesis should be implanted (> $21 \mathrm{~mm}$ labelled size) to allow for a better haemodynamic profile if a subsequent valve-in-valve TAVI becomes necessary. These findings may provide an impetus to employ more bioprostheses, rather than mechanical valves, in younger patients undergoing open SAVR in the near future, given that this effective technique of replacing a failed surgical bioprosthesis is available.

\section{REFERENCES}

1. Makkar RR, Fontana GP, Jilaihawi $\mathrm{H}$, et al; PARTNER Trial Investigators. Transcatheter aortic-valve replacement for inoperable severe aortic stenosis. N Engl J Med 2012; 366:1696-704.

2. Popma JJ, Adams DH, Reardon MJ, et al; CoreValve United States Clinical Investigators. Transcatheter aortic valve replacement using a self-expanding bioprosthesis in patients with severe aortic stenosis at extreme risk for surgery. J Am Coll Cardiol 2014; 63:1972-81.

3. Kodali SK, Williams MR, Smith CR, et al; PARTNER Trial Investigators. Two-year outcomes after transcatheter or surgical aortic-valve replacement. N Engl J Med 2012; 366:1686-95.

4. Adams DH, Popma JJ, Reardon MJ. Transcatheter aortic-valve replacement with a self-expanding prosthesis. N Engl J Med 2014; 371:967-8.

5. Webb JG, Wood DA, Ye J, et al. Transcatheter valve-in-valve implantation for failed bioprosthetic heart valves. Circulation 2010; 121:1848-57.

6. Bedogni F, Laudisa ML, Pizzocri S, et al. Transcatheter valve-in-valve implantation using Corevalve Revalving System for failed surgical aortic bioprostheses. JACC Cardiovasc Interv 2011; 4:1228-34.

7. Eggebrecht $\mathrm{H}$, Schäfer $\mathrm{U}$, Treede $\mathrm{H}$, et al. Valve-in-valve transcatheter aortic valve implantation for degenerated bioprosthetic heart valves. JACC Cardiovasc Interv 2011; 4:1218-27.

8. Dvir D, Webb J, Brecker S, et al. Transcatheter aortic valve replacement for degenerative bioprosthetic surgical valves: results from the global valve-in-valve registry. Circulation 2012; 126:2335-44.

9. Dvir D, Webb JG, Bleiziffer S, et al; Valve-in-Valve International Data
Registry Investigators. Transcatheter aortic valve implantation in failed bioprosthetic surgical valves. JAMA 2014; 312:162-70.

10. Zoghbi WA, Chambers JB, Dumesnil JG, et al; American Society of Echocardiography's Guidelines and Standards Committee; Task Force on Prosthetic Valves; American College of Cardiology Cardiovascular Imaging Committee; Cardiac Imaging Committee of the American Heart Association; European Association of Echocardiography; European Society of Cardiology; Japanese Society of Echocardiography; Canadian Society of Echocardiography; American College of Cardiology Foundation; American Heart Association; European Association of Echocardiography; European Society of Cardiology; Japanese Society of Echocardiography; Canadian Society of Echocardiography. Recommendations for evaluation of prosthetic valves with echocardiography and doppler ultrasound: a report From the American Society of Echocardiography's Guidelines and Standards Committee and the Task Force on Prosthetic Valves, developed in conjunction with the American College of Cardiology Cardiovascular Imaging Committee, Cardiac Imaging Committee of the American Heart Association, the European Association of Echocardiography, a registered branch of the European Society of Cardiology, the Japanese Society of Echocardiography and the Canadian Society of Echocardiography, endorsed by the American College of Cardiology Foundation, American Heart Association, European Association of Echocardiography, a registered branch of the European Society of Cardiology, the Japanese Society of Echocardiography, and Canadian Society of Echocardiography. J Am Soc Echocardiogr 2009; 22:975-1014; quiz 1082-4.

11. Kappetein AP, Head SJ, Généreux P, et al. Updated standardized endpoint definitions for transcatheter aortic valve implantation: the Valve Academic Research Consortium-2 consensus document. Eur Heart J 2012; 33:2403-18.

12. Brennan JM, Edwards FH, Zhao Y, et al; DEcIDE AVR (Developing Evidence to Inform Decisions about Effectiveness-Aortic Valve Replacement) Research Team. Long-term safety and effectiveness of mechanical versus biologic aortic valve prostheses in older patients: results from the Society of Thoracic Surgeons Adult Cardiac Surgery National Database. Circulation 2013; 127:1647-55.

13. Pibarot $P$, Dumesnil JG. Hemodynamic and clinical impact of prosthesispatient mismatch in the aortic valve position and its prevention. J Am Coll Cardiol 2000; 36:1131-41

14. Chiam PT, Ewe SH. An update on complications associated with transcatheter aortic valve implantation: stroke, paravalvular leak, atrioventricular block and perforation. Future Cardiol 2013; 9:733-47. 